\title{
The Effects of Human Socioeconomic Status and Cultural Characteristics on Urban Patterns of Biodiversity
}

\author{
Ann P. Kinzig 1 , Paige Warren, Chris Martin, Diane Hope, and Madhusudan Katti
}

\begin{abstract}
We present evidence that there can be substantial variation in species richness in residential areas differing in their socioeconomic and cultural characteristics. Many analyses of the impacts of urbanization on biodiversity rely on traditional "urban-to-rural" gradient measures, such as distance from urban center or population density, and thus can fail to account for the ways in which human socioeconomic and cultural characteristics are shaping the human-environment interaction and ecological outcomes. This influence of residential values and economic resources on biodiversity within the urban matrix has implications for human quality of life, for urban conservation strategies, and for urban planning.
\end{abstract}

Key Words: avian biodiversity; human-environment interaction; plant biodiversity; urban biodiversity; urban ecology

\section{INTRODUCTION}

Humans have become a global environmental force, altering biogeochemical processes across unprecedented spatial scales and at unprecedented rates (Clark et al. 1993, Vitousek et al. 1997). Cities represent one of the most profound modifications of the Earth's surface (Redman 1978, Collins et al. 2000), and at some point in the early part of this century, more people will live in cities than in rural environments. This means that the daily interaction with nature for most people will come from their yards, streets, and neighborhood parks. If access to adequate environmental amenities-including aesthetic and recreational opportunities - is considered fundamental for sustainability and quality of life, then we should be working to ensure a better understanding of ecological patterns and processes in the places most people call home (Harrison et al. 1987, Lubchenco et al. 1991).

As humans reshape the Earth's surface, other species will increasingly find themselves subject to a shifting mosaic of land-use types, from lightly to heavily human dominated (Kinzig and Grove 2000). The most profoundly altered areas-like citieshave often been viewed as irrelevant for conservation. We now know that successful conservation requires implementing landscape plans that encompass all land-use types, including cities, which can host valued species (Soulé and Terborgh 1999). Thus, promoting regional conservation in urbanizing areas requires understanding the patterns of biodiversity within and around cities.

Many studies focusing on urban patterns of biodiversity use a "gradient approach," e.g., searching for regular patterns of biodiversity relative to gradients of land use, distance from urban center, or human population density (e.g., Germaine and Wakeling 2001, Blair 1999). Although factors such as distance from urban center do not directly influence biodiversity, they do serve as surrogates for other causal mechanisms, such as disturbance regimes, percent cover, pollutant load, or predation pressure. One assumption implicit in the gradient approach, as it has been applied to date, is that the characteristics of the human population occupying a particular portion of the landscape matter very little-we need only know how closely they live together (e.g., population density) or their preference for the urban fringe (e.g., distance from urban center) to capture the ways in which their 
activities will influence patterns of biodiversity within the urban matrix. By this argument, 1000 Hmong refugees living in a square kilometer on the urban fringe should have the same influence on biodiversity as 1000 people of northern European heritage transplanted from Illinois; such an outcome runs contrary to intuition. Nonetheless, these traditional approaches have improved our understanding of the structure of biological communities in and around urban areas. The results we present here, however, suggest that the traditional gradient measures might best be served by augmenting them with a consideration of the characteristics of human populations interacting with the ecological systems (Collins et al. 2000).

The ethnobotanical, urban horticultural, and anthropological literatures indicate the need for such an inclusion. Individuals may be socialized by their cultural backgrounds and social histories to prefer different landscapes, including constructed landscapes; for example, placing different emphasis on the number and type of flowering plants, canopy structure, proportion of native plants, or percent vegetative cover (e.g., Odum 1970, Kaplan and Talbot 1988, Fraser and Kenney 2000). Moreover, groups differ in their economic status, and thus in the resources they can devote to creating their ecological ideal. If such cultural influences and economic constraints are strong enough, and people of similar socioeconomic and cultural status cluster in the urban matrix (as we know they do), then ecological analysis may be missing an important additional "gradient" as it seeks to understand and distill urban patterns of biodiversity (Hope et al. 2003). Incorporating such a socioeconomic gradient in our analyses may not only improve our predictive ability, but also alter our perceptions of humanenvironment interactions as we acknowledge that the preferences, desires, and wherewithal of the people in the landscape matter. They are not merely an exogenous perturbing force, but an interactive species on the landscape, structuring their surroundings to achieve a particular suite of environmental amenities.

In this paper, we offer a conceptual framework for understanding when we may need to go beyond traditional gradient analysis, and include gradients of socioeconomic and cultural characteristics to explain urban patterns of biodiversity. We test this conceptual framework in Phoenix, Arizona using avian and plant diversity within neighborhood parks and residential areas. Our results show that significant variation in biodiversity can and does occur in neighborhoods of different types, above and beyond that which can be explained using traditional gradient measures.

\section{Conceptual Framework}

Not all patterns of urban biodiversity should be equally affected by the socioeconomic or cultural status of the human residents. In particular, different organisms in different locations will differ in the degree of bottom-up and top-down human influences. Bottom-up influences reflect the integrated outcomes of small-scale (individual or household) choices or actions, and thus should reflect the cultural, social, or economic differences among the smaller groups making decisions. Topdown influences reflect city-level management strategies and decisions. Within the context of a single city, these should be relatively more neutral toward the status of the citizens in question (although we recognize that politics and persuasion can erode some of this neutrality, particularly with respect to those ecological features that may be highly valued and can be manipulated directly). Both bottom-up and top-down influences can be intentional (intended manipulation of a particular ecological process or condition) or incidental (ecological impacts that are not the intended goal of the focal activity). We recognize in employing the terms "top down" and "bottom up" that they differ from the traditional uses in the ecological literature, being more consistent with use in political or social literatures. Nonetheless, we feel these terms capture and describe differences in the ways in which different people at different levels of organization (household vs. government) are interacting with the landscape.

We select four biodiversity patterns expected to differ in their sensitivity to socioeconomic and cultural characteristics, as follows:

- Perennial plant diversity in parks is largely controlled by top-down processes, including, most prominently, municipal decisions concerning landscaping and management. There may be some modest bottom-up influences reflecting individual or household choices or actions, including, for example, lobbying for particular park designs. Because the dominant influence is top down, and 
because these decisions are expected to be driven more by efficiency or aesthetics than by the status of different served groups, plant diversity in parks is not expected to vary with socioeconomic or cultural characteristics.

- Perennial plant diversity in neighborhoods is largely controlled by bottom-up processes, including, most prominently, household landscaping choices. There may be some modest top-down control exerted by citymanaged plantings on public property, or by imposed agreements concerning appropriate landscaping practices, but the dominant influence is bottom up. Because of this, plant diversity in neighborhoods is expected to vary significantly with socioeconomic or cultural characteristics.

- Bird diversity in parks and neighborhoods is controlled by both top-down and bottom-up processes. Because birds are mobile, they range across a variety of patches, including those that are publicly and privately controlled. Both public and private choices will, therefore, influence the availability of food, habitat, predation, and nesting sites. Thus, bird diversity in parks and neighborhoods is expected to show moderate variation with socioeconomic or cultural characteristics. Because bird diversity in parks is likely more strongly controlled by top-down choices concerning park design and management, whereas bird diversity in neighborhoods will show a greater influence of household choices, bird diversity in neighborhoods is expected to be more sensitive to socioeconomic and cultural characteristics than bird diversity in parks, but the mobility of birds between parks and their neighborhoods is expected to make this difference small.

In some ways, these predictions may seem self evident. If household behaviors are strongly structuring the urban environment, and household behaviors vary by socioeconomic or cultural status, then we would expect to see significant variation in biodiversity across neighborhoods of different types. And yet traditional gradient analysis assumes that other influences - such as population density (a typical surrogate for fragmentation), distance from urban center (a typical surrogate for degree of disturbance), or land use - are likely to be stronger. We may not need to include socioeconomic or cultural conditions at all if such socioeconomic influences are weak relative to the other ways in which humans impact biodiversity in urban settings, or if the household behaviors influencing ecological features really don't vary much across people of differing status.

Thus, this preliminary analysis allows us to understand the degree to which augmentation of traditional gradient analysis may be needed, and whether an inclusion of socioeconomic and cultural measures improves our ability to predict patterns of urban biodiversity. Our predicted results are shown in Fig. 1.

To test these predictions we use an on-going study of ecological and social processes in small urban parks and their surrounding neighborhoods in Phoenix, Arizona. These parks are located in high-, medium-, and low-income residential neighborhoods, with correlated variation in education levels, housing type, and ethnicity. The parks have common features, including ballfields, playgrounds, open grassy areas, and trees. Similarly, the parks are all located in residential neighborhoods. Figure 2 shows one of our 16 parks, located in a middleincome neighborhood.

\section{METHODS}

\section{Site Selection}

We have categorized neighborhoods using the Claritas PRIZM data set, which relies on a variety of primary data sources, including census and purchasing data, to divide neighborhoods into one of 62 "lifestyle clusters." These 62 clusters are further aggregated into 15 "social groups" that have similar economic status, ethnic make-up, education level, employment opportunities, and housing type/ family arrangements (Weiss 2000). We acquired 1990 Claritas data for the Phoenix area, and used it to classify neighborhoods surrounding each park managed by the Phoenix Parks Department. (Cluster assignments from the 2000 Census were not available at the time of site selection. The Claritas data are used for site selection only; more up-to-date 2000 Census data have been used in our statistical analyses below.) 
Fig. 1. Patterns of biodiversity considered in this paper, and predictions concerning how they will vary relative to socioeconomic and cultural gradients.

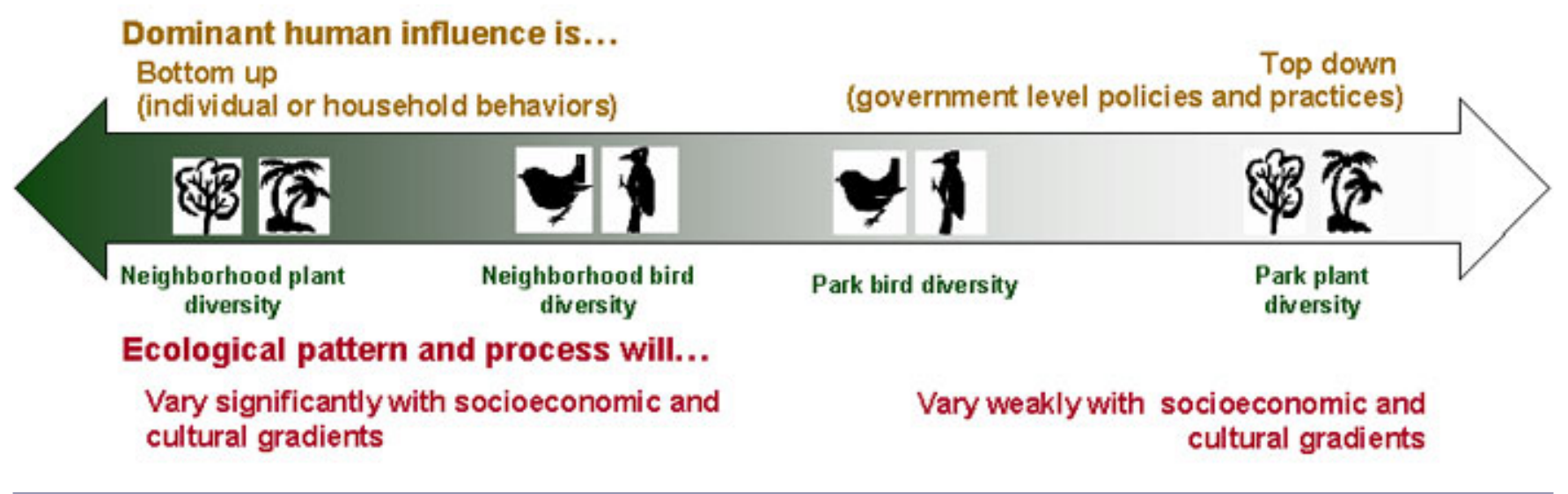

We chose parks in the $0.02-0.06 \mathrm{~km}^{2}$ (4-15 acres) range; parks of this size are classified as "neighborhood" parks by the Phoenix Parks Commission; 49 Phoenix parks fall within this size range. We were seeking parks in high- to mediumdensity neighborhoods (urban to suburban) and in high-, medium-, and low-income clusters; therefore, we focused on four different social groups that encompassed this range. These were Elite Suburban (high income and education, white plus Asian immigrants); Inner Suburbs and Urban Midscale (middle to middle-low income, high ethnic diversity, mixed education); and Second City Blues (low income, Black and Hispanic, highschool education). The two middle-income social groups were aggregated into a single middle-income category for purposes of statistical analysis and illustration. Thirty of our 49 candidate parks were located in Census block groups assigned to one of these four social groups. Park-goers, however, can come from neighboring block groups (the Phoenix Parks Department characterizes the "walk to" distance to neighborhood parks as a half mile). To isolate the influence of socioeconomic and cultural status, we wanted relatively homogeneous neighborhoods in the area around each park. Therefore, we only selected parks where block groups within a half mile fell into the same social cluster assignments, reducing the number of available parks to 20 . Then, we eliminated parks that were: (a) storm-water retention basins $(n=2)$, (b) too dangerous $(n=1)$, or (c) fenced with controlled access $(n=1)$. This left 16 parks: five each in high- and medium-income areas, and six in lower-income areas. Figure 3 shows a distribution of our focal parks within Phoenix.

We recognize that this method of park selection introduces other gradients as well, including those that co-vary with socioeconomic and cultural status. The most notable of these is geographic positionour upper-income parks are largely situated to the north (four out of five); our middle-income parks are situated to the west; and our lower-income parks are, with one exception, clustered in the south. This illustrates one of the many challenges of working in an urban environment-namely, the inability to control for all variables in accessible sites. For purposes of our research, however, controlling for relative homogeneity in the surrounding neighborhoods was more important than controlling for landscape position, although we can (and do) include landscape position in our statistical analyses.

We also recognize the potential value of having a greater number of sites. Nonetheless, our sample size is large enough to see some statistically significant patterns, and we did select nearly all Phoenix parks for which there was a homogeneous neighborhood (according to Claritas data) surrounding the park. We did not want to expand our sample to other municipalities, to ensure that 
Fig. 2. One of our 16 focal parks, showing playground equipment, vegetation, open areas, and picnic tables.

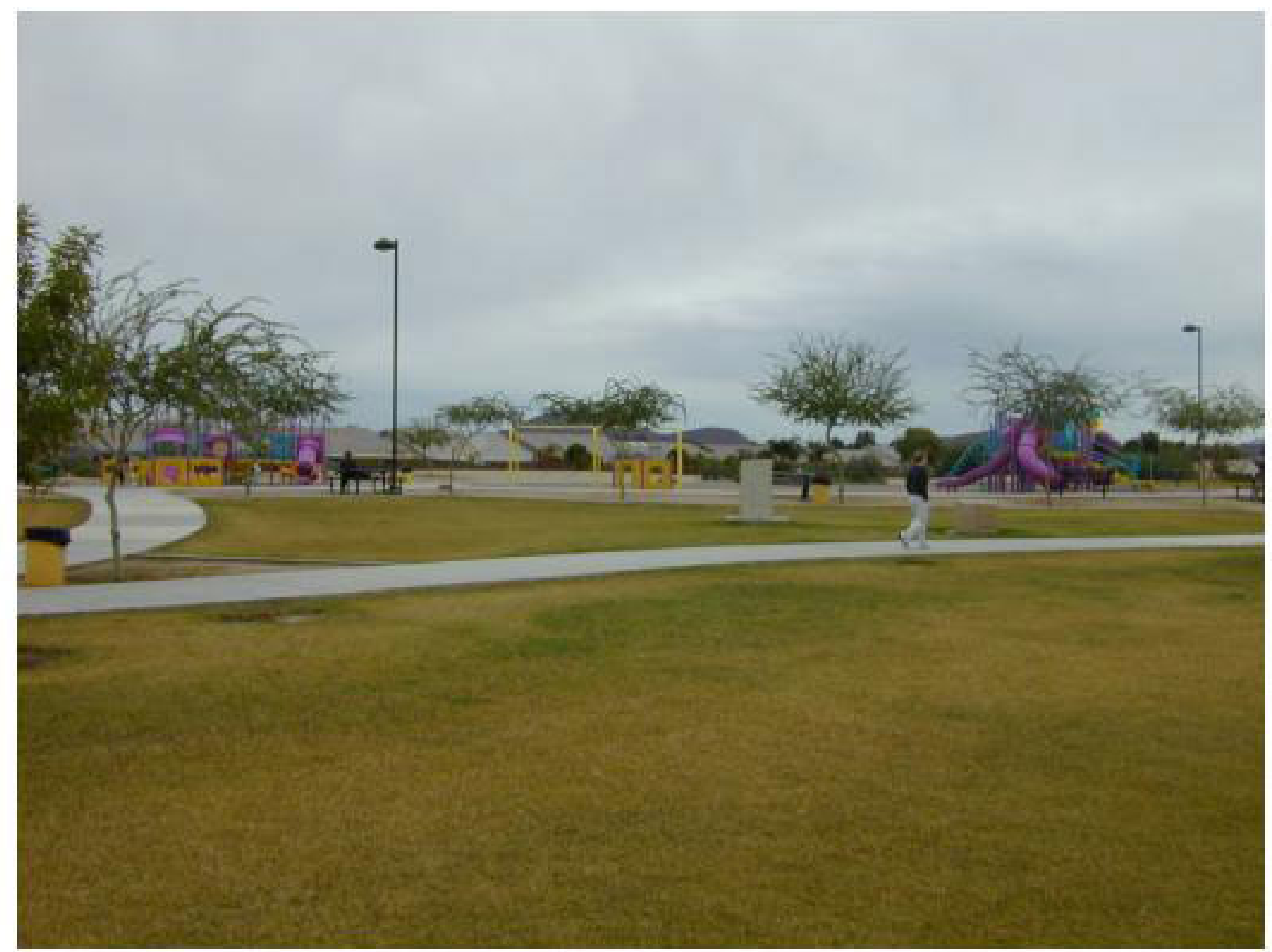

park management practices were uniform across our sample. Moreover, this is a pilot study designed to examine the interaction of urban citizens with urban green spaces. As such, we deemed it appropriate to gather more data on fewer sites; data gathered in each park and its surrounding neighborhood included plant and avian diversity and abundance, park use, landscaping preferences (mail-out survey), noise, cat abundance, bird-feeding behaviors, and presence of livestock.

\section{Socioeconomic Classification}

We used U.S. Census 2000 data to supplement the categorical PRIZM classification with continuous variables in the statistical analysis. Social, ethnic, and economic variables are highly correlated in the Census data (e.g., median family income and percent Latino-Hispanic are highly correlated, as is median family income and education level). Because of this high degree of correlation, we select only one variable-median family income-as a surrogate for both cultural and economic status. 
Fig. 3. The distribution of our focal parks within Phoenix. Dark green shows high socioeconomic status; light green shows low socioeconomic status.

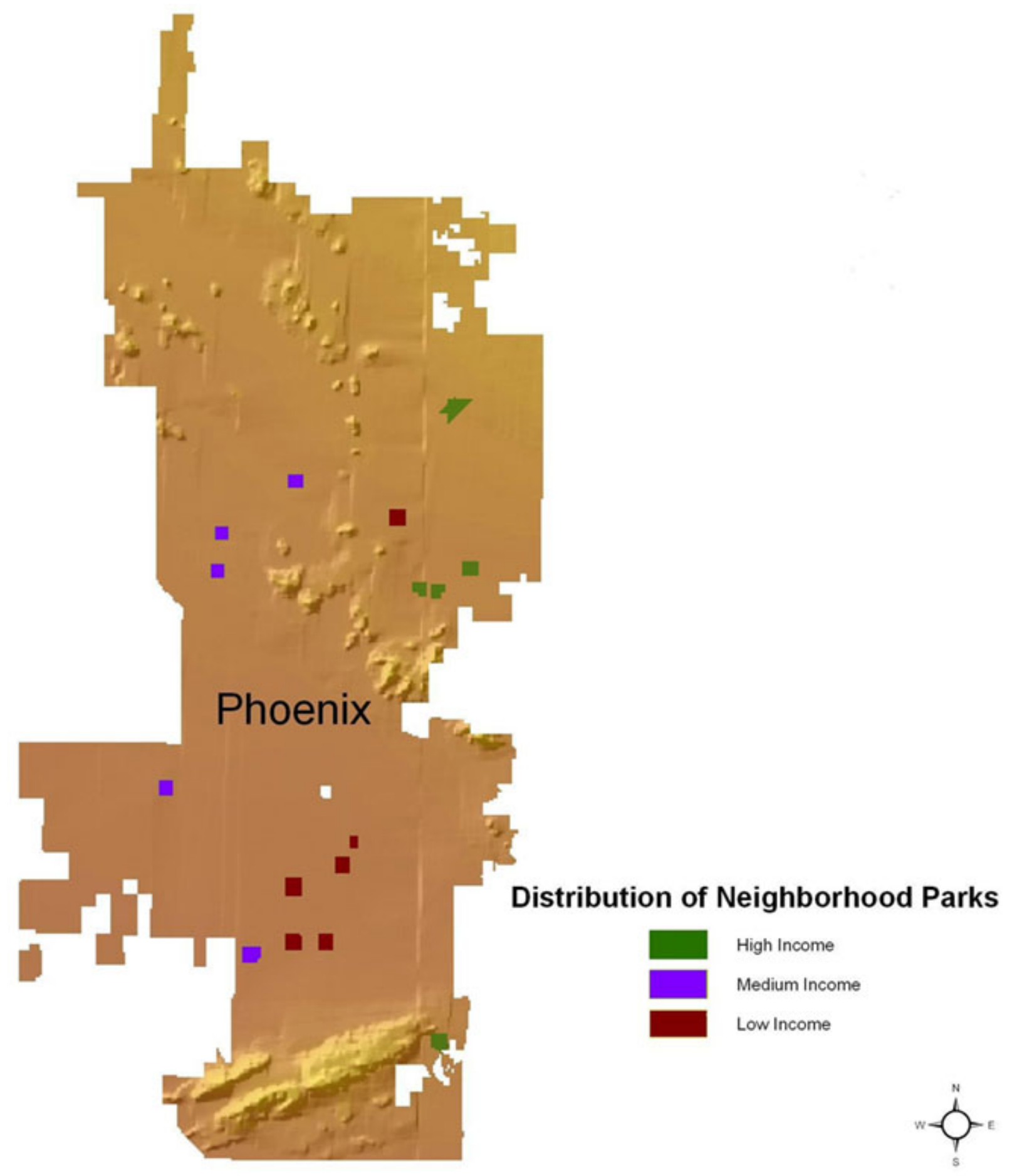




\section{Avian Diversity}

Avian species richness was tabulated by conducting 15-minute point counts at the center of each park, or at each of the neighborhood sites $(100 \mathrm{~m}$ from the park boundary in four cardinal directions). Three observers visited each point within a month-long window during the winter (Dec.-Jan.), spring migration (Mar.-Apr.), summer (Jun.-Jul.), and fall migration (Sep.-Oct.) seasons 2001. In the statistical models, we use cumulative annual data for species richness; the seasonal patterns do not differ significantly from annual patterns.

\section{Perennial Plant Diversity}

We identified every perennial plant to the finest taxonomic level possible, usually the species level, in each of the focal parks (summer 2001), and along four 200-m transects in the neighborhoods around the park (summer to fall 2001). (Transects were centered on the bird observation points; $\mathrm{N}-\mathrm{S}$ vs. EW orientation randomly assigned.) We refer to these unique plant taxa as "species," although some are species groups, hybrid taxa, or horticultural varieties.

We recognize, for both birds and plants, that there are other important measures of diversity, including abundance and community composition patterns. Although we are studying these aspects of diversity, space precludes reporting on those here.

\section{Measuring Influence of Neighborhood Status}

A fair test of the efficacy of traditional gradient approaches (e.g., those employing population density, distance from urban center, etc. to explain patterns of urban biodiversity) relative to socioeconomic gradient approaches would include a larger range of population density and distance from urban center than we have included in this study. Thus, we do not attempt to conclude anything about the superiority of traditional vs. socioeconomic variables. Instead, we are asking whether socioeconomic effects on diversity are independent of the effects of variables used in traditional gradient analyses. If socioeconomic effects are independent, predictability should be improved by their inclusion. Moreover, we would expect this improved predictability to follow our hypotheses above (e.g., greatest improvement for neighborhood plant diversity; least improvement for park plant diversity; intermediate improvement for neighborhood and park avian diversity). Thus, we first examined the effectiveness of median household income in capturing patterns of urban biodiversity (Table 1) ("socioeconomic gradient measures only"). We then used a model incorporating only traditional gradient variables (population density, median year structure built, and distance from urban center), and added to that the socioeconomic variable (median family income), assessing the partial $p$-value for this forced addition.

Note that an alternative for "distance from urban center" would be $\mathrm{N}-\mathrm{S}$ and $\mathrm{E}-\mathrm{W}$ position; this may be particularly appropriate given the location of our parks (Fig. 3). We repeated all of our analyses with $\mathrm{N}-\mathrm{S}$ and $\mathrm{E}-\mathrm{W}$ position substituted for distance from urban center; these analyses do not change the results or our conclusions. We also included proximity to large desert parks in many of our statistical analyses; including this variable did not change our conclusions about the relative importance of socioeconomic status in structuring urban patterns of biodiversity.

We also performed a stepwise regression to determine whether traditional or socioeconomic variables explained a greater proportion of observed variation in species richness (see Table 1).

The species richness values for each park and neighborhood, along with values of the independent variables, are given in Table 2.

\section{RESULTS}

We tested two overall propositions: 1) That different human groups interact differently with the environment in urban settings, and that, therefore, adding socioeconomic variables to traditional gradient analysis should improve predictability for urban biodiversity patterns; and 2) that addition of the socioeconomic variable will be most significant for neighborhood plant diversity, followed by neighborhood avian diversity, park avian diversity, and park plant diversity (see Fig. 1). The $R^{2}$ values give a preliminary indication of the influence of a single socioeconomic variable (median family income) on urban patterns of biodiversity. Median family income appears to be most effective in explaining neighborhood plant diversity, and least 
Table 1. Multiple regression analyses for traditional gradient measures and socioeconomic gradient measures. The influence of neighborhood socioeconomic status is expected to decrease from left to right. The effect of adding income (a socioeconomic factor) to a model containing the traditional gradient measures is shown by the partial $p$-value for income. Partial $p$-values were predicted to increase from left to right. The remaining cells contain the $F$-ratios for each independent variable in the model and adjusted $R^{2}$ values for total models. Significance is indicated as: $\dagger p<0.1 ; * p<0.05 ; * * p<0.01 ; * * * p<0.001$; ****p< 0.0001 . A greater number of *'s indicates a greater level of statistical significance, making it more likely that bird or plant diversity is influenced by the variable(s) of interest.

\begin{tabular}{|c|c|c|c|c|}
\hline & Neighborhood & & Park & \\
\hline Independent Variables ${ }^{\mathrm{a}}$ & $\begin{array}{l}\text { \# plant } \\
\text { species } \\
(n=16)\end{array}$ & $\begin{array}{l}\# \text { bird } \\
\text { species } \\
(n=16)\end{array}$ & $\begin{array}{l}\text { \# bird } \\
\text { species } \\
(n=16)\end{array}$ & $\begin{array}{l}\text { \# plant } \\
\text { species } \\
(n=16)\end{array}$ \\
\hline \multicolumn{5}{|c|}{$\begin{array}{l}\text { Socioeconomic gradient measures } \\
\text { only }\end{array}$} \\
\hline $\begin{array}{l}\text { Median household income, } F \\
\text { ratio }^{\mathrm{a}}\end{array}$ & 81.7 & 11.3 & 32.3 & 1.26 \\
\hline Total Model adjusted $R^{2}$ & $0.84 * * * *$ & $0.41 * *$ & $0.68 * * * *$ & 0.02 \\
\hline \multicolumn{5}{|c|}{ Traditional gradient measures only } \\
\hline Population density ${ }^{\mathrm{a}}$ & $11.44 * *$ & 0.03 & $4.31 \dagger$ & 2.05 \\
\hline Median year structure built ${ }^{\mathrm{a}}$ & 1.22 & 0.46 & 0.10 & $3.69 \dagger$ \\
\hline Distance from urban center ${ }^{b}$ & $15.36^{* *}$ & $3.87 \dagger$ & $4.21 \dagger$ & 0.48 \\
\hline Total Model adjusted $R^{2}$ & $0.65 * *$ & 0.15 & $0.48 *$ & $0.33 \dagger$ \\
\hline \multicolumn{5}{|l|}{$\begin{array}{l}\text { Adding socioeconomics to } \\
\text { traditional model: }\end{array}$} \\
\hline $\begin{array}{l}\text { Partial } p \text {-value of median } \\
\text { household income }\end{array}$ & 0.001 & 0.051 & $\mathbf{0 . 0 2 0}$ & 0.942 \\
\hline Total Model adjusted $R^{2}$ & $0.86 * * * *$ & $0.36 \dagger$ & $0.66 * *$ & 0.27 \\
\hline \multicolumn{5}{|l|}{ Stepwise regression } \\
\hline Order of loading & $\begin{array}{l}\text { Median household } \\
\text { income } \\
\text { Population Density } \\
\text { \% Hispanic-Latino }\end{array}$ & $\begin{array}{l}\text { Median household } \\
\text { income }\end{array}$ & $\begin{array}{l}\text { Median household } \\
\text { income } \\
\text { Median year } \\
\text { structure built } \\
\% \text { Hispanic-Latino }\end{array}$ & $\begin{array}{l}\text { Median year } \\
\text { structure built }\end{array}$ \\
\hline Total Model $R^{2}$ & $0.90 * * * *$ & $0.45 * *$ & $0.67 * *$ & $0.45^{* *}$ \\
\hline
\end{tabular}

Notes:

a) Population density, median year structure built, median household income, and percent Hispanic-Latino taken from U.S. Census 2000 data for the census tract in which the park is located. Neighborhood observation points were only included in the analysis if they fell within this census tract (three out of four, or four out of four points or transects for all neighborhoods).

b) There is a strong N-S and E-W influence on the distribution of parks in neighborhoods of different socioeconomic status (Fig. 4). Substituting N-S or E-W position for distance from urban center does not 
change the overall conclusions of the statistical analysis.

effective in explaining park plant diversity, as expected (adjusted $\mathrm{R}^{2}$ values for "socioeconomic gradient measures only"-Table 1). Median family income has intermediate efficacy in explaining patterns of park and neighborhood avian diversity. A similar pattern is found for traditional gradient measures, with the highest $R^{2}$ values associated with neighborhood plant diversity and the lowest associated with park plant diversity, although the socioeconomic model gives higher $R^{2}$ values, and more significant results for every case but park plant diversity. (Comparing $R^{2}$ values is the best and perhaps only way to compare two models with the same independent variables and different dependent variables, but the results must be interpreted with caution. $R^{2}$ values can be sensitive to many things, including the accuracy of measurement of the dependent and independent variables. Given the methods used, plant diversity measures are likely to be more accurate than avian diversity measures; similarly, independent variables may vary in accuracy. Thus, the differences between the $R^{2}$ values for the models predicting bird diversity might be lower due simply to measurement accuracy. On the other hand, plant diversity in parks was, if anything, the most accurately measured variable, as plants were exhaustively counted and identified within parks. Thus, the low $R^{2}$ values for park plant diversity relative to the other models should be viewed as a robust result.)

We do have a statistical test for the independence of socioeconomic variables from traditional gradients: the partial $p$-values associated with adding a socioeconomic factor to a more traditional gradient model. This gives another indication of the sensitivity of the biodiversity measure of interest to the socioeconomic status of the residents in the surrounding neighborhood. As predicted, there is a significant effect of adding socioeconomic status to the model for plant diversity in neighborhoods (partial $p$-value $=0.001$ ), but an insignificant effect of adding socioeconomic status for plant diversity in parks (partial $p$-value $=0.942$ ). Neighborhood and park avian diversity once again showed intermediate sensitivity to adding socioeconomic status with one $p$-value only marginally significant (partial $p$-value $=0.051$ and 0.020 , respectively). The odds of finding partial $p$-values less than 0.1 for all three of the predicted measures by chance alone is 0.001 , according to Moran's calculation (Moran 2003). Thus, the data strongly supported our predictions.

\section{DISCUSSION AND CONCLUSIONS}

Our results indicate that augmenting traditional gradient analysis with consideration of the cultural and economic characteristics of residents occupying different urban neighborhoods improves understanding of patterns of biodiversity within the urban matrix. The results presented here need to be more widely tested before generalizations can be made, but neighborhood socioeconomic and cultural status appears to be playing an important role in structuring urban biodiversity patterns, independent of the effects of population density, distance from urban center, or time since disturbance (median year structure built). In a previous study in Phoenix (Hope et al. 2003) plant diversity in 92 randomly selected $30 \times 30 \mathrm{~m}$ plots within the urban matrix increased significantly with the economic status of the residents in the surrounding Census block group. This gives us confidence that the similar relationship found in our smaller study is representative of patterns that may well apply to the entire metropolitan Phoenix region. The complex ways in which socioeconomic and cultural conditions can influence urban biodiversity, however, suggests additional insights into the mechanisms underlying these patterns are needed.

Neighborhood differences in species richness can be substantial. We recorded, for instance, an average of 28 avian species in high-income parks during 2001 , compared with only 18 avian species in lowincome parks (Fig. 4). All non-native species are found in all parks; thus, this distinction is driven by the presence of native avian species (see Fig. 5).

Residents of lower socioeconomic status are thus simply less likely to be able to enjoy diverse plant and bird communities in their neighborhoods. Scientists and managers should be concerned with this for two reasons. First, inequitable access to "nature" in the places where people spend most of their time has environmental justice implications. Quality of life can be influenced by our 
Table 2. Summary data for the 16 parks, including species-richness data and independent variables used in the statistical analysis

\begin{tabular}{|c|c|c|c|c|c|c|c|c|}
\hline \multirow[b]{2}{*}{ Park Name } & \multicolumn{4}{|c|}{ Species Richness Measures } & \multicolumn{2}{|c|}{$\begin{array}{l}\text { Socioeconomic and } \\
\text { Ethnic Variables }\end{array}$} & \multicolumn{2}{|c|}{$\begin{array}{l}\text { Traditional Gradient } \\
\text { Analysis Variables }\end{array}$} \\
\hline & $\begin{array}{l}\text { Total \# } \\
\text { Plant S- } \\
\text { pecies in } \\
\text { Park }\end{array}$ & $\begin{array}{l}\text { Total \# } \\
\text { of Bird } \\
\text { Species in } \\
\text { Park }\end{array}$ & $\begin{array}{l}\text { Mean \# of Bird } \\
\text { Species in } \\
\text { Neighborhood }^{\mathrm{a}}\end{array}$ & $\begin{array}{l}\text { Mean \# of Plant } \\
\text { Species in } \\
\text { Neighborhood }^{\mathrm{a}}\end{array}$ & $\begin{array}{l}\text { Median H- } \\
\text { ousehold } \\
\text { Income }\end{array}$ & $\begin{array}{l}\text { \% Hispanic- } \\
\text { Latino }\end{array}$ & $\begin{array}{l}\text { Population } \\
\text { Density (p- } \\
\text { eople/ha) }\end{array}$ & $\begin{array}{l}\text { Median Year } \\
\text { Structures } \\
\text { Built }\end{array}$ \\
\hline Altadena & 12 & 24 & 20 & 66 & $\$ 59278$ & 8.0 & 22.0 & 1973 \\
\hline Cashman & 51 & 33 & 21.5 & 66.25 & $\$ 65658$ & 5.2 & 2.36 & 1997 \\
\hline Cholla Cove & 23 & 23 & 25 & 59 & $\$ 52878$ & 4.4 & 12.8 & 1983 \\
\hline Sonrisa & 12 & 28 & 19.5 & 63 & $\$ 70496$ & 5.5 & 8.92 & 1975 \\
\hline Western Star & 31 & 28 & 21 & 50.67 & $\$ 60580$ & 9.5 & 22.4 & 1983 \\
\hline Country Gables & 6 & 28 & 17.5 & 45.5 & $\$ 41569$ & 17 & 23.9 & 1974 \\
\hline Lindo & 17 & 28 & 20 & 49 & $\$ 36143$ & 58 & 10.4 & 1975 \\
\hline Orme & 8 & 24 & 25 & 45 & $\$ 39022$ & 69 & 26.7 & 1958 \\
\hline Werner's Field & 15 & 24 & 20 & 52 & $\$ 42062$ & 8.5 & 24.3 & 1985 \\
\hline Westown & 11 & 17 & 19 & 45.5 & $\$ 38165$ & 16 & 26.6 & 1974 \\
\hline Eastlake & 32 & 17 & 13.5 & 30 & $\$ 20278$ & 63 & 16.1 & 1980 \\
\hline Edison & 12 & 15 & 16.5 & 19.5 & $\$ 15174$ & 80 & 28.8 & 1961 \\
\hline Harmon & 15 & 19 & 14.5 & 19 & $\$ 10607$ & 78 & 34.0 & 1962 \\
\hline Hayden & 19 & 16 & 16 & 22.5 & $\$ 23902$ & 82 & 27.7 & 1967 \\
\hline Nueve & 17 & 18 & 15.5 & 36.67 & $\$ 26111$ & 82 & 13.5 & 1966 \\
\hline Palomino & 11 & 20 & 18.75 & 21.5 & $\$ 29029$ & 56 & 39.3 & 1983 \\
\hline
\end{tabular}

Notes:

a) These numbers are an average of the number of species observed at each of the neighborhood observation points (birds) or across the 200-m neighborhood transects (plants) that fell within the census tract containing the park.

b) Values for Census tracts surrounding parks. Data taken from 2000 U.S. Census.

surroundings, and one might argue that the poor have an even greater need for access to nature and environmental amenities in their neighborhood than do the rich, given that they are less likely to be able to travel to enjoy such amenities, or create them in their gardens. Urban planners and policymakers need to examine the ways in which they can ameliorate the inequitable access to urban nature for the poor: through judicious management of public spaces, consideration of how the distribution of upper- and lower-income neighborhoods might influence larger-scale biodiversity patterns, and recognition of the disproportionate impact certain zoning practices may have in neighborhoods that are already ecologically depauperate. Second, as the world becomes increasingly urban, a greater 
Fig. 4. Measures of species (generic) richness vs. median neighborhood income for a) perennial plants in neighborhoods; b) birds in neighborhoods; c) birds in parks; and d) perennial plants in parks. Biodiversity is expected to be less sensitive to neighborhood socioeconomic status as we move from top to bottom.
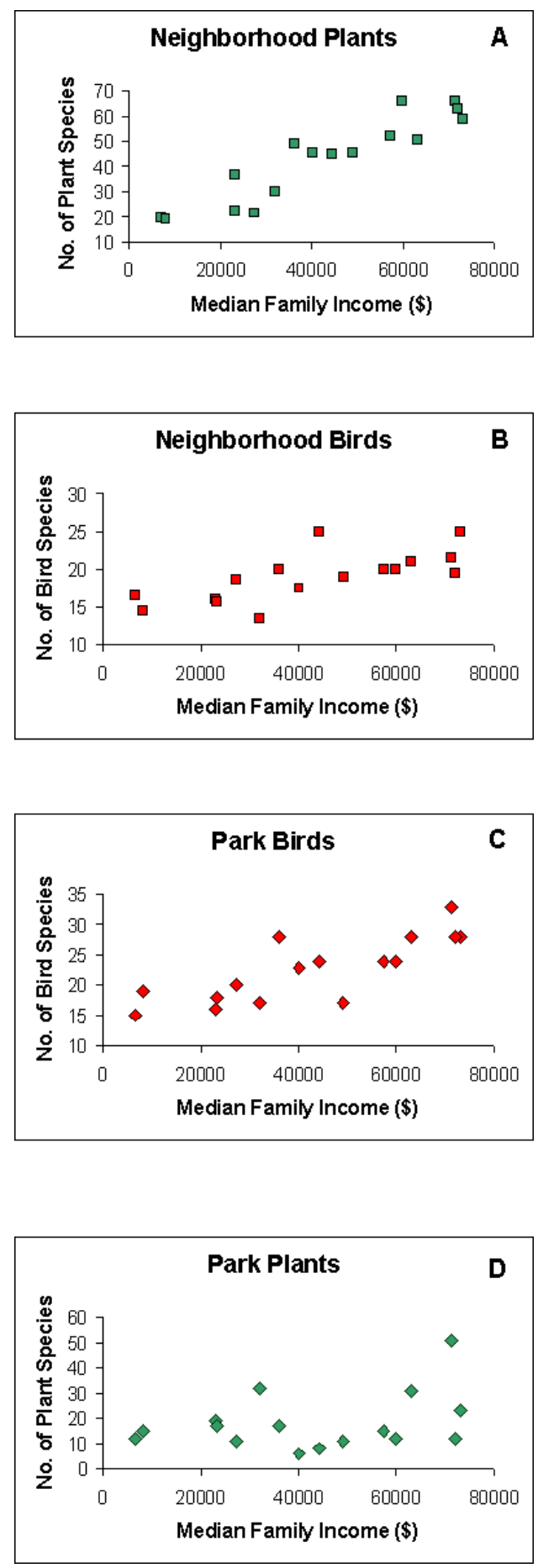

View HTML Version 
Fig. 5. Some native Arizona bird species found exclusively in upper-income neighborhoods. Photos by Jim Russo (http://birdcentral.net/) A) Cactus wren (Catherpes mexicanus); B) Hooded Oriole (Icterus cucullatus); and C) Black-tailed gnatcatcher (Polioptila melanura).
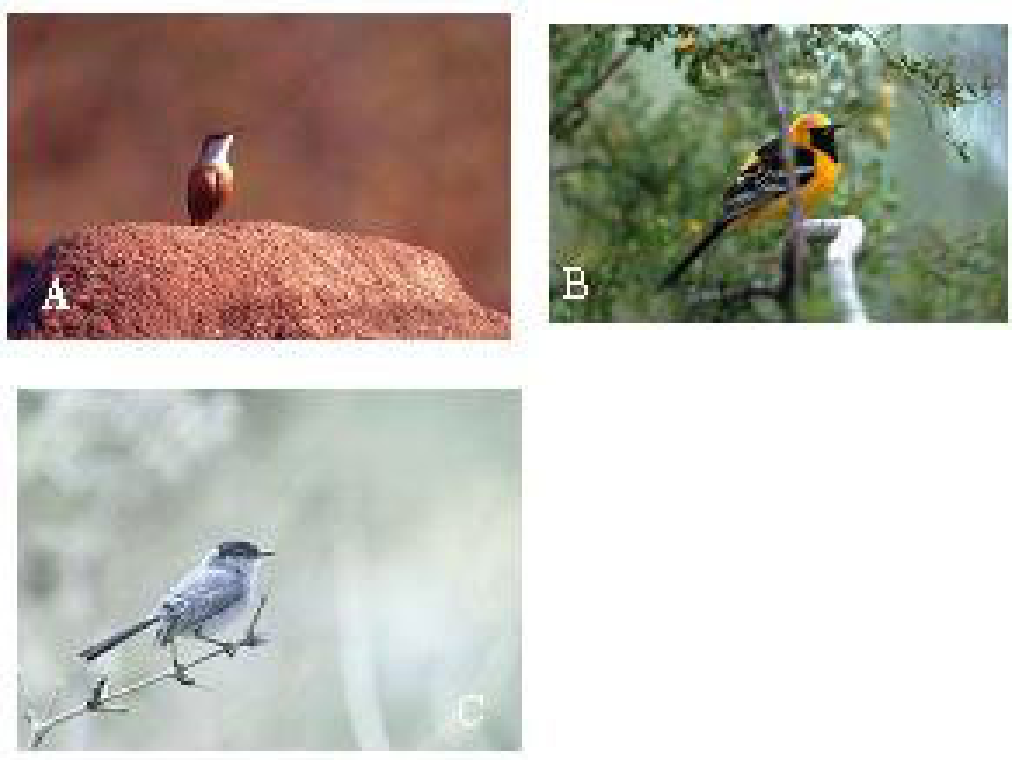

number of global residents will have their primary interactions with nature in an urban setting. Our collective conservation ethic and philosophies of "proper" human-environment relationships will increasingly spring from these urban experiences. Lack of access to urban nature may have implications for how those ethics and relationships develop in the future.

Finally, our current models for understanding what processes influence urban biodiversity may be inadequate. Humans are not simply an outside perturbing force, depressing biodiversity whenever they interact with the environment. And cities are not irrelevant for conservation, however widespread the belief that they are might be. Instead, many species live in and move through urban and other human-dominated systems, with implications for larger regional patterns of biodiversity. Nearly all of the human population growth in the next 30 years is expected to be in urban areas (both through urban births and rural to urban migration - see National Research Council 2003). If scientists and conservationists cannot find ways to effectively incorporate an understanding of how humans, particularly urban residents, are interacting with and influencing their surroundings, then they risk failures in those areas of the world where the window of opportunity for conserving species may be closing most rapidly.

Responses to this article can be read online at: http://www.ecologyandsociety.org/vol10/iss1/art23/responses/

\section{Acknowledgments:}

We thank Charles Redman, Eyal Shochat, Corinna Gries, and four anonymous reviewers for helpful comments on an earlier version of this manuscript, and Radha Kunda for help with the figures. This research was supported through the Central Arizona-Phoenix Long-Term Ecological Research Station (NSF \#DEB-9714833). 


\section{LITERATURE CITED}

Blair, R. B. 1999. Birds and butterflies along an urban gradient: surrogate taxa for assessing biodiversity? Ecological Applications 9:164-170.

Clark, W. C., R. W. Kates, B. L. Turner, J. F. Richards, and W. B. Meyer, editors. 1993. The Earth as transformed by human action. Cambridge University Press, Cambridge, UK.

Collins, J. P., A. Kinzig, N. B. Grimm, W. F. Fagan, D. Hope, J. Wu, and E. T. Borer. 2000. A new urban ecology. American Scientist 88:416425 .

Fraser, E. D. G., and W. A. Kenney. 2000. Cultural background and landscape history as factors affecting perceptions of the urban forest. Journal of Arboriculture 26:106-112.

Germaine, S. S., and B. F. Wakeling. 2001. Lizard species distributions and habitat occupation along an urban gradient in Tucson, Arizona, USA. Biological Conservation 97:229-237.

Harrison, C., M. Limb, and J. Burgess. 1987. Nature in the city: popular values for a living world. Journal of Environmental Management 25(4):347_ 362.

Hope, D., C. Gries, W. Zhu, W. F. Fagain, C. L. Redman, N. B. Grimm, A. L. Nelson, C. Martin, and A. P. Kinzig. 2003. Socioeconomics drive urban plant diversity. Proceedings of the National Academy of Sciences 100:8788-8792.

Kaplan, R., and J. F. Talbot. 1988. Ethnicity and preference for natural settings: a review and recent findings. Landscape and Urban Planning 15:107117.

Kinzig, A. P., and J. M. Grove. 2000. Urbansuburban ecology. Pages 733-746 in S. Levin, editor. The encyclopedia of biodiversity. Academic Press, Inc., San Diego, California, USA.

Lubchenco, J., A. M. Olson, L. B. Brubaker, S. R. Carpenter, M. M. Holland, S. P. Hubbell, S. A. Levin, J. A. MacMahon, P. A. Matson, J. M. Melillo, H. A. Mooney, C. H. Peterson, J. R. Pulliam, L. A. Real, P. J. Regal, and P. G. Risser. 1991. The sustainable biosphere initiative: an ecological research agenda: a report from the
Ecological Society of America. Ecology 72(2):371412.

May, R. M., J. H. Lawton, and N. E. Stork. 1995. Assessing extinction rates. Pages 1-24 in J. H. Lawton and R. M. May, editors. Extinction rates. Oxford University Press, Oxford, UK.

Moran, M. D. 2003. Arguments for rejecting the sequential Bonferroni in ecological studies. Oikos 100:403-405.

National Research Council. 2003. Cities transformed: demographic change and its implications in the developing world. M. R. Montgomery, R. Stren, B. Cohen, and H. Reed, editors. Panel on urban population dynamics. Committee on population. National Academy Press, Washington, D.C., USA.

Odum, H. T. 1970. Environment, power, and society. Wiley-Interscience, New York, New York, USA.

Redman, C. L. 1978. The rise of civilization: early farmers to urban society in the ancient Near East. W. H. Freeman and Company, New York, New York, USA.

Soulé, M. E., and J. Terborgh. 1999. Conserving nature at regional and continental scales-a scientific program for North America. Bioscience 49:809-817

Vitousek, P., H. A. Mooney, J. Lubchenco, and J. M. Melillo. 1997. Human domination of Earth's ecosystems. Science 277:494-499.

Warren, P.S., A.P. Kinzig, and C. Martin. Human socioeconomic factors are better predictors of urban bird diversity than vegetation structure. Ecology: submitted.

Weiss, M. J. 2000. The clustered world: how we live, what we buy, and what it all means about who we are. Little, Brown, and Co., Boston, Massachussetts, USA. 